\title{
ANALISIS PERSONAL HYGIENE DAN KONDISI SANITASI NARAPIDANA PADA LAPAS KLAS IIB CIANJUR
}

\author{
Irman Raka Firmansyah \\ Politeknik Ilmu Pemasyarakatan, Prodi Teknik Pemasyarakatan. Jl.Raya Gandul, Kec. Cinere \\ Kota Depok Jawa Barat 16514 \\ E-mail: irmanraka48@gmail.com
}

\begin{abstract}
A healthy environment is an ecological balance that must exist between humans and the environment in order to guarantee a healthy condition of humans. This study aims to determine how the state of personal hygiene and sanitary conditions contained in Cianjur Class II Prison. This research was conducted in the form of qualitative research with phenomenological approach, namely by conducting interviews with 10 informants, where 2 main informants were interviewing the polyclinic and casibinadik health workers. The research was conducted from 29 January to 25 February 2020 in Lapas IIB Cianjur. The results of the study showed the results of the analysis related to personal hygiene conditions and sanitary conditions of prisoners in Prison Class IIB Cianjur can be concluded that in terms of personal hygiene in each individual prisoner is already good in hand and nail hygiene, cleanliness of clothes, towels and cleanliness of his bed. And in terms of sanitation, clean water, rubbish and latrines are good enough and cleanliness is always maintained by them by organizing a daily picket system in maintaining the cleanliness of the rooms in each block. The author suggests to Cianjur Class IIB Lapas officers to further increase supervision on each supervision of cleanliness in each block, and conduct health education for personal hygiene and sanitation environment sanitation to increase awareness of prisoners that hygiene must always be maintained so that they are not susceptible to disease.
\end{abstract}

Keywords: Personal hygiene, Sanitation, Correctional Institution

\begin{abstract}
Abstrak
Lingkungan yang sehat merupakan suatu keseimbangan ekologi yang harus terdapat antara manusia dan lingkungan agar terjaminnya keadaan yang sehat dari manusia. Penelitian ini bertujuan untuk mengetahui bagaimana keadaan personal hygiene dan kondisi sanitasi yang terdapat di Lapas Klas IIB Cianjur. Penelitian ini dilakukan dalam bentuk penelitian kualitatif dengan pendekatanfenomenologi yaitu dengan melakukan serta Interview dengan 10 informan, dimana 2 informan utama merupakan dlam melakukan Interview yaitu petugas kesehatan poliklinik dan kasibinadik, penelitian dilaksanakan mulai dari 29 Januari hingga 25 Februari 2020 di Lapas Klas IIB Cianjur. Hasil penelitian menunjukan hasil analisis terkait kondisi personal hygiene dan kondisi sanitasi narapidana di Lapas Klas IIB Cianjur dapat ditarik kesimpulan bahwa dari segi personal hygiene pada setiap individu narapidana sudah baik dalam kebersihan tangan dan kuku, kebersihan berpakaian, handuk dan kebersihan tempat tidurnya. Dan dari segi kondisi sanitasi air bersih,sampah dan jamban sudah cukup baik dan kebersihannya selalu dijaga oleh mereka dengan mengadakan sistem piket harian dalam menjaga kebersihan
\end{abstract}




\begin{abstract}
kamar pada setiap bloknya. Penulis menyarankan kepada petugas Lapas Klas IIB Cianjur agar lebih meningkatkan pengawasan lagi pada setiap pengawasan terhadap kebersihan pada setiap bloknya, serta melakukan penuluhan kesehatan untuk personal hygiene dan kebersihan lingkungan sanitasi agar meningkatkan kesadaran pada narapidana bahwa kebersihan harus selalu terjaga agar mereka tidak mudah terserang penyakit.
\end{abstract}

Kata Kunci: Personal hygiene, Sanitasi, Lembaga Pemasyarakatan

\section{PENDAHULUAN}

Lingkungan yang sehat merupakan suatu keseimbangan ekologi yang harus terdapat antara manusia dan lingkungan agar terjaminnya keadaan yang sehat dari manusia. Terdapat lingkup kesehatan pada lingkungan meliputi : penyediaan air minum, pengelolaan air buangan serta pengendalian terhadap pencemaran, pembuangan sampah padat, pencegahan/pengendalian pencemaran tanah oleh ekskreta manusia, hygiene makanan termasuk hygiene susu, pengendalian pencemaran udara, pengendalian radiasi, kesehatan kerja, pengendalian kebisingan, perumahan dan pemukiman, aspek kesehatan lingkungan dan transportasi udara, perencanaan daerah perkotaan, pencegahan kecelakaan, rekreasi umum dan pariwisata, tindakan-tindakan sanitasi yang saling berhubungan dengan adanya epidemi atau wabah, bencana alam serta perpindahan penduduk, tindakan pencegahan yangdiperlukan untuk menjamin lingkungan(1) Kondisi lingkungan yang sehat dapat mendukung tumbuhnya perilaku hidup sehat, mempengaruhi kesehatan jasmani maupun rohani, serta dapat terhindar dari efek yang merugikan bagi kesehatan. Kebersihan lingkungan merupakan salah satu factor utama dalam mewujudkan hidup sehat. Menurut teori H.L Blum, derajat kesehatan dipengaruhi oleh 4 (empat) faktor yaitu lingkungan, perilaku, pelayanan kesehatan dan keturunan. Dari keempat factor tersebut, di negara yang sedang berkembang, factor perilaku dan factor lingkungan mempunyai peranan yang sangat besar terhadap peningkatan derajat kesehatan masyarakat(2)
Mengacu pada ketentuan Permenkumham Nomor 13 Tahun 2018 tentang Syarat Dan Tata Cara Pemberian Remisi, Asimilasi, Cuti Mengunjungi Keluarga, Pembebasan Bersyarat, Cuti Menjelang Bebas, Dan Cuti Bersyarat, narapidana adalah sebagaimana dimaksud dalam Undang- undang Nomor 12 Tahun 1995 tentang Pemasyarakatan. Kemudian dijelaskan dalam pasal 1 angka 7 Undang- Undang Nomor 12 Tahun 1995 tentang Pemasyarakatan bahwa narapidana atau WBP merupakan terpidana yang telah atau sedang menjalani hukuman pidana hilang kemerdekaan di Lembaga Pemasyarakatan. serta diatur dalam pasal 1 angka 4 Permenkumham RI Nomor 6 Tahun 2013 tentang Tata Tertib Lembaga Pemasyarakatan dan Rumah Tahanan Negara bahwa narapidana adalah terpidana yang menjalani pidana hilang kemerdekaan di Lembaga Pemasyarakatan Sehingga penulis dapat menyimpulkan bahwa narapidana yakni seseorang yang sedang menjalani hukuman sehingga hilangnya kemerdekaan yang dia miliki di Lembaga Permasyarakatan.(3)

Lembaga Pemasyarakatan Klass IIB Cianjur adalah salah satu Unit Pelaksana Teknispada kantor wilayah Kementerian Hukum dan Ham Jawa Barat memiliki fungsi sebagai tempat pembinaan terhadap Warga Binaan Pemasyarakatan (WBP) atau narapidana.

\section{BAHAN DAN METODE}

Jenis penelitian ini adalah kualitatif dengan pendekatan fenomenologi, yaitu 
dengan melakukan pengamatan, dan Indepth Interview atau wawancara mendalam untuk memperoleh keterangan dengan cara Tanya jawab dan tatap muka dengan informan meggunakan pedoman wawancara. Lokasi Penelitian dilaksanakan di Lapas Klas IIB Cianjur dan penelitian ini dilakukan pada bulan Januari - Februari 2020. Dalam penentuan informan peneliti menggunakan teknik Purposive. Merupakan penentuan informan tidak didasarkan atas strata dan kedudukan. Pengumpulan informasi akan dihentikan apabila terjadi informasi berulang atau kejenuhan informan. Karena, penelitian kualitatif tidak dipersoalkan dari jumlah sampel. Adapun Informan dalam penelitian ini yaitu, Informan kunci adalah mereka yang dapat memberikan informasi secara jelas dan terpercaya, yakni narapidana yang berjumlah 8 orang di Lapas Klas IIB Cianjur dan Informan Utama berjumlah 2 orang yaitu terdiri dari Kasibinadik dan Petugas Kesehatan Klinik Lapas Klas IIB Cianjur.

\section{HASIL}

Data Narapidana yang terdapat pada Lapas Klas IIB Cianjur pada bulan Januari dan Februari yaitu terdiri dari :

Tabel 1. Data narapidana bulan Januari dan Februari 2020 Lapas Klas IIB Cianjur.

\begin{tabular}{|l|l|l|l|l|l|l|l|l|}
\hline \multirow{2}{*}{ No } & \multirow{2}{*}{ periode } & \multicolumn{4}{|l|}{ Tahanan } & \multirow{2}{*}{ total } \\
\cline { 3 - 10 } & & DL & DP & TD & AL & AP & TA & \\
\hline 1 & Januari & 203 & 9 & 212 & 0 & 0 & 0 & 212 \\
\hline 2 & Februari & 212 & 11 & 223 & 1 & 0 & 1 & 224 \\
\hline
\end{tabular}

\begin{tabular}{|l|l|l|l|l|l|l|l|l|}
\hline \multicolumn{4}{|l|}{ Narapidana } & \multirow{2}{*}{ total } & kapasitas & $\begin{array}{l}\text { Tahanan \& } \\
\text { Narapidana }\end{array}$ \\
\cline { 1 - 5 } DL & DP & TD & AL & AP & TA & & & 828 \\
\hline 613 & 3 & 616 & 0 & 0 & 0 & 616 & 355 & 843 \\
\hline 617 & 2 & 619 & 0 & 0 & 0 & 619 & 355 & 843 \\
\hline
\end{tabular}

Sumber : SDP Lapas Klas IIB Cianjur tanggal 20 Februari 2020(4)

Dari data di atas menunjukan bahwa saat ini kondisi Lapas Klas IIB Cianjur menunjukan over kapasitas hal ini tentu memicu terjadinya gangguan kesehatan terhadap narapidana, apabila petugas tidak memperhatikan dengan baik kesehatan narapidana tersebut hal ini akan berdampak pada penyebaran dan penularan penyakit antar sesama narapidana.

\section{PEMBAHASAN}

Penelitian mengenai analisis kondisi sanitasi dan personal hygiene di Lapas Klas IIB Cianjur telah dilakukan untuk mengetahui bagaimana kondisi sanitasi dan personal hygiene narapidana dengan didapatnya hasil dari 10 sampel penelitian didapat hasil sebagai berikut : 
Dari hasil wawancara dapat disimpulkan bahwa air bersih yang digunakan untuk mandi dan mencuci sudah memenuhi syarat. Hal ini dapat kita liat bagaimana sampel banyak mengatakan air didalam kamar mandi setiap blok atau kamar sudah cukup bersih. Kemudian Informan Ahli yaitu Petugas Lapas menambahkan penjelasan mengatakan bahwa kondisi air bersih yang narapidana gunakan untuk mandi, mencuci dan lain-lain sudah cukup baik tidak ada masalah dari segi bau, warna maupun rasa. Saya selaku peneliti melakukan tindakan dengan melihat langsung kondisi air bersih diblok kamr mandi narapidana, air bersihnya cukup baik, tidak berbau, berasa dan berwarna.

Dari hasil wawancara dengan informan utama dapat ditarik kesimpulan bahwa sampah yang berada dilingkungan lapas dan di masing-masing blok narapidana selalu dibersihkan dan diangkut oleh mobil sampah dan terkadang juga sampah hanya langsung

dibuang ke TPS terdekat, tetapi kebersihan dilingkungan lapas sudah bagus tidak ada sampah yang terhambur dan berceceran meskipun belum ada pemilahan secara spesifik kesampah basah dan sampah kering.

Dari jawaban informan utama mengatakan bahwa sampah dikelola dengan baik selalu ada pengankutan selama 1 hari sekali ke TPA dan setiap harinya selalu rutin buang sampah di TPS dengan menggunakan jadwal piket harian.Dalam penjelasan informan utama dapat di tarik kesimpulan bahwa kebersihan selalu dijaga dengan melakukan pembersihan secara rutin untuk tetap menjaga kebersihan jamban atau WC di setiap blok kamar narapidana dan mereka juga ada pembagian piket disetiap harinya.(5) Dari jawaban informan kunci diatas bahwa mereka mengatakan jamban disetiap kamar mandi narapidana sudah terpelihara dengan baik karena mereka menggunakan jadwal piket harian secara bergantian dalam membersihkan jamban disetiap kamar mandi. Semua informan yang ada pada penelitian ini memang beranggapan bahwa kebersihan Saluran Pembuangan Air Limbah Kamar Mandi di lingkungan Lapas sudah cukup bagus dan memadai tidak tersumbat dan lancar mengalir ke pembuangan. Dari hasil wawancara dengan informan utama dapat disimpulkan bahwa (SPAL) Saluran Pembuangan Air Limbah sudah mengalir dengan baik karena selalu di cek setiap hari oleh petugas. Dari hasil wawancara bersama responden dan dari beberapa pertanyaan didapatkan hasil bahwa dari kebersihan pakaiannya sudah cukup baik Dari hasil wawancara bersama responden dapat disimpulkan bahwa kebersihan tangan dan kuku sudah cukup baik, setelah diambil dari beberapa pertanyaan yaitu apakah mencuci tangan setelah membersihkan tempat tidur, apakah memotong kuku seminggu sekali, apakah mencuci tangan menggunakan sabun setelah (BAB) Buang Air Besar / (BAK) Buang Air Kecil dan apakah mereka mencuci tangannya setelah menggaruk badan. Dari hasil wawancara dengan 2 informan utama sebagai pendukung dapat disimpulkan bahwa dari personal hygiene nya sebagaian besar narapidana cukup baik dengan dilihat dari hasil wawancara yang mencakup dari beberapa poin pertanyaan yaitu dari kebersihan pakaian, kebersihan tangan dan kuku, kebersihan handuk dan kebersihan tempat tidur dari semua pertanyaan itu mereka tahu dan mereka sadar akan kebersihan diri mereka sendiri selama berada didalam blok kamar, namun hanya ada dua narapidana yang personal hygiene nya buruk. Serta dengan adanya penyuluhan secara individu kepada narapidana pada saat mereka pertama masuk di dalam Lembaga Pemasyarakatan membuat mereka paham 
akan pentingnya kebersihan bagi diri masingmasing.

\section{KESIMPULAN}

Kondisi pada sanitasi dari air bersih, sampah, jamban serta SPAL di lingkungan Lembaga Pemasyarakatan Cianjur cukup baik tidak ada masalah dari air bersih yang mereka gunakan sehari-hari baik dari bau, warna, dan rasa dengan begitu mereka bisa menggunakan air untuk keperluan mandi dan lain-lain dengan nyaman. Serta untuk sampah rutin dilakukan pengangktan ke TPA setiap 1 hari sekali dan setiap pagi selalu membuang sampah di TPS. Kemudian untuk menjaga bersihnya jamban disetiap kamar mandi narapidana kebersihannya selalu dijaga dengan mengadakan piket bergantian setiap harinya tetapi ada pula inisiatif dari narapidana dengan melakukan iuran perorang untuk membeli pembersih jamban atau WC. Dan untuk SPAL karena petugas rutin mengontrol maka jarang terjadi masalah penyumbatan atau gangguan lainnya, sehingga tidak ada tersumbat ataupun meluapnya aliaran SPAL, akan tetapi petugas masih harus terus memberikan penyuluhan terkait kebersihan kepada seluruh narapidana secara rutin baik narapidana yang sudah lama maupun narapidana yang baru masuk kedalam Lapas hal ini tentu akan menjadi pemicu peningkatan kebersihan pada diri setiap narapidana sehingga diharapkan setiap narapidana memiliki jasmani dan rohani yang sehat.

\section{UCAPAN TERIMA KASIH}

Dengan terselesaikannya Karya Ilmiah ini, penulis mengucapkan terimakasih yang sebesar-besarnya kepada :

1. Tuhan Yang Maha Kuasa untuk segala berkat dan karunianya sehingga penulis dapat menyelesaikan Karya Ilmiah ini
2. Kedua orang tua saya yang memberikan dukungan dan semangat selama pengerjaan Karya Ilmiah ini

3. Teman-teman Politeknik Ilmu Pemasyarakatan angkatan 51 yang memberikan motivasi selama penulis melakukan penelitian.

4. Petugas pada Lapas Klas IIB Cianjur yang bersedia memberikan saran masukan selama pelaksanaan penelitian.

\section{DAFTAR RUJUKAN}

1. Hermawan Y. Pengaruh Penyuluhan Kesehatan Lingkungan Terhadap Tingkat Pengetahuan Dan Pelaksanaan Kesehatan Lingkungan Smp Negeri Tambaksari Kecamatan Tambaksari Kabupaten Ciamis. Bumi Lestari. 2013;13(1):166-73.

2. Kesehatan F, Sam M. Gambaran Kesehatan Lingkungan Sekolah Di Wilayah Kerja Puskesmas Tongkaina Tahun 2018 Pendahuluan Upaya kesehatan lingkungan merupakan salah satu cara yang dilakukan untuk mewujudkan kualitas lingkungan yang sehat, baik fisik , kimia , biologi dan sosial. 2018;7(5).

3. Menkumham. Permenkumhan RI Nomor 13 Tahun 2018 tentang Syarat dan Tata Cara Pemberian Resmi, Asimilasi, Cuti, Mengunjungi Keluarga, Pembebasan Bersyarat, Cuti Menjelang Bebas dan Cuti Bersyarat. Kemenkumham. 2018;Nomor 3(282):1-86.

4. Pemasyarakatan SD. Jumlah Narapidana per Januari 2020. 2020.

5. Guntur K. Gambaran Faktor-Faktor Yang Berpengaruh Terhadap Abstrak penduduk dengan akses jamban sehat belum sesuai target, hal ini dipengaruhi beberapa faktor Description Of Factors Affecting 
DOI: http://dx.doi.org/10.35329/jkesmas.v6i1
Towards Coverage Of Healthy.
2018;8(1):56-62. 